\title{
Impact Analysis of Education Level for Job Perception and Job Performance of PDOs in Karnataka State, India
}

\author{
M.V. Bharamagoudar* and J.G. Angadi \\ Department of Agricultural Extension Education, College of Agriculture, \\ U.A.S, Dharwad, India \\ *Corresponding author
}

\begin{abstract}
A B S T R A C T

\begin{tabular}{|c|}
\hline Keywords \\
\hline $\begin{array}{l}\text { PDO, Job } \\
\text { perception, job } \\
\text { performance, } \\
\text { education, } \\
\text { Karnataka }\end{array}$ \\
\hline Article Info \\
\hline $\begin{array}{l}\text { Accepted: } \\
\text { 30 December } 2018 \\
\text { Available Online: } \\
\text { 10 January } 2019\end{array}$ \\
\hline
\end{tabular}

The present study was undertaken to analyze the Job perception and job performance of Panchaya Development officers in Karnataka State during the year 2013-2014. The study area includes Dharwad, Haveri, Bagalkot and Bijapur districts of northern Karnataka. The Ex-post facto' research design was employed for the study. Further, the PDOs working in Dharwad, Haveri. Bagalkot and Bijapur districts were selected as the population for the study. From each districts 38 PDOs were selected by simple random sampling to form total sample of 152 respondents'. The results show that, although majority of PDOs belonged to medium job performance category, critical look at the results revealed that 22.92 per cent of graduates showed high performance in their job when compared to master degree holders, they had lower job performance with an difference 26.79 per cent. In addition, among selected variables, Age variable had a positive and significant relationship with job perception of PDOs. Age of majority of PDOs varied between 25-30 years. The findings also show that, positive and significant relationship was recorded between job involvement of PDOs and job perception.
\end{abstract}

\section{Introduction}

As the transition from the old development to the new people management materializes, the human resource function is beginning play a role much broader in scope, much stronger in its impact, and much more pertinent in its effect, the continuously rising need for competitiveness can only result in continuously changing role boundaries for human resource management Singh and Vijayaragavan (2014). The success of an organization depends largely on the performance of its human resources and also their perception towards job Victoria and Benjamin (2012). To determine the contributions of each individual, it is necessary to have minimum education criteria with clearly stated standards. Carefully defined Panchayath Development officers (PDOs) performance standards that are reliable, strategically relevant, and free from either criterion deficiency or contamination of are essential foundations for organization future. In many organizations, performance and perception are seen as a necessary tool to improve the productivity of employees Subbarao (2001). The degree to which the 
performance and perception program, benefits the organization and its members is directly related to the quality of the job activities that are conducted Maity et al., (2011). Interviewing skills are best developed through instruction and supervised practice Shamna et al., (2012). In this context it is worthwhile to know Education level for Job perception and job performance of PDOs in Karnataka State and also to know factors associated in analyzing the impact of education on PDOs Job performance and Job perception.

\section{Materials and Methods}

The details of the steps followed in developing the appropriate methodology for measuring job perception and performance of PDOs are discussed below.

\section{Job perception of PDOs}

First, Identification of components followed by Identification of statements where the Statements scrutiny/editing of the statements were carried out and Relevancy weightage by panel of judges, The judgments were used to work out the relevancy weightage (RW) of each statement as given below:

Relevancy Weightage $(\mathrm{RW})=$

Most relevant x $2+$ Relevant $\mathrm{x} 1+$ Not relevant $\mathrm{x} 0$

Maximum possible score $(40$ x $2=80)$

Considering the relevancy weightage, the statements were screened for their relevancy. Accordingly, the statements having relevancy weightage of more than or equivalent to 0.75 were selected. Finally, 22 statements were retained i.e. five for Planning and Development of programmes, seven for Implementation of Programmes, seven for Working Environment and three for
Documentation work. After this, Validity of the scale to measure the job perception of PDOs was ascertained by assessing content validity and construct validity. Followed by Content validity and Construct validity and reliability was also tested. The process of Administration and scoring of job perception was done using 3 categories mentioned below. The final scale consisted of 22 statements which are to be administered to the PDOs on five point continuum viz., Strongly agree, Agree, Undecided, Disagree and Strongly disagree, with the score of 5,4,3,2 and 1 respectively. The perception scores of all the job items were summated to get the job perception score of PDO. The scores range from 22 to 110, a higher score revealed higher job perception PDO.

The PDOs were grouped into three categories based on mean and standard deviations.

Less favourable - Below (X- S.D.)

Favourable - Between (X + S.D.) and (X S.D.)

More favourable- Above (X + S.D.)

\section{Job performance of PDOs}

The process of scale development involved several deliberate steps. The details of the steps followed in developing the scale to measure the job performance of PDOs are discussed below.

First to Identification of statements followed by Statements scrutiny/editing of the statements and relevancy weightage, it was finalized to total of, 16 statements were retained. The Validity and content validity and reliability was done. Finally the, Administration and scoring of job performance reveals using the below mentioned details such as The final scale consisting of 16 statements was administered to the PDO on five point continuum viz., 
Excellent, Good, Satisfactory, Poor and very poor, with the score of $5,4,3,2$ and 1 respectively. The performance scores of all the job statements were summated to get the job performance score of PDO. The scores ranged from 16 to 80 , a higher score revealed higher job performance of the PDO.

The respondents were grouped into three categories based on mean and standard deviations.

\begin{tabular}{|l|l|}
\hline Category & Score \\
\hline Light & Below (X - S.D.) \\
\hline Medium & $\begin{array}{l}\text { Between (X + S.D.) } \\
\text { and (X - S.D.) }\end{array}$ \\
\hline High & Above (X + S.D.) \\
\hline
\end{tabular}

\section{Results and Discussion}

Majority of the PDOs irrespective of their degree belonged to medium level of job perception (Table 1). The results are mentioned in the following 3 subheads.

Although majority of PDOs belonged to medium job performance category, critical look at the Table revealed that 22.92 per cent of graduates showed high performance in there job. Interesting, 26.79 per cent of master degree holders had low job performance.

Association of personal and job related characteristics of PDOs with job perception and job performance

The results of correlation between personal and job related characteristics of PDOs and their levels of job perception and job performance are presented in Table 2.

The results revealed that, out of eight selected independent variables, three variables namely age, job satisfaction and facilities and resources exhibited positive and significant relationship with job perception of PDOs at 1 per cent level of probability. While, education and job involvement showed positive and significant relationship at 5 per cent level of probability. Further, information seeking behaviour, perceived workload and job stress did not show any relationship with job perception of PDOs.

Five variables namely age, education, job satisfaction, job involvement and facilities and resources exhibited positive and significant relationship with job performance of PDOs at 1 per cent level of probability. Whereas, job stress revealed negative and significant relationship with job performance. Further, information seeking behaviour and perceived workload did not show any relationship with the job performance of PDOs.

Association of personal and job related characteristics of PDOs with dependent variables

\section{Relationship between independent variables with job perception}

\section{Age and job perception}

Age had a positive and significant relationship with job perception of PDOs. Age of majority of PDOs varied between 2530 years. It is because the cadre was created in the year 2008. Even then, age had a positive and significant relationship with job perception of PDOs. As we all know, experience is a good teacher. As the age of the PDOs advanced, they had a clear picture of job and its expectations. Therefore, as the age advanced, their job became clearer and clearer.

\section{Education and job perception}

The results of the study indicated that education showed significant relationship 
with job perception. Through education one acquires knowledge, improves skills and their attitude gets modified which has a clear influence on their job perception. Most of PDOs were bachelor degree holders since, graduation is the minimum qualification prescribed for the post. Post graduates had a clear perception of job Nagananda (2005). Maturity that is gained through age and experience has contributed for better perception of their job.

\section{Information seeking behaviour and job perception}

The results portrayed in the Table 18 indicated that there was non-significant relationship between information seeking behaviour of the PDOs and their job perception. This finding implied that the job perception of PDOs was unaffected by their extent of information seeking behaviour. It was further noticed that when the PDOs were analyzed for their information seeking behaviour, they were homogenous with respect to the use of mass media for acquisition of job related information. The findings of Bosco (2000) and Nagananda (2005) corroborate with the above findings.

\section{Perceived work load and job perception}

Perceived workload of the respondents exhibited a non significant relationship with job perception because there was no much variation in the perception of their workload.

Similar results were reported by Sontakki (1995) and Nagananda (2005).

\section{Job involvement and job perception}

A positive and significant relationship was recorded between job involvement of PDOs and job perception. This finding in other words meant that higher the degree of psychological identification and active involvement in the job by PDOs, more favourable was the situation for favourable job perception and vice-versa.

The job of the PDOs demands more efforts in order to get acquainted with the day to day developments, which calls for a greater degree of involvement. It is quite natural that those who involve more in their job identify themselves with the job and perform better. This finding was similar to the findings of Bosco (2000) and Nagananda (2005).

\section{Job stress and job perception}

There existed a negative significant relationship between job stress and job perception of PDOs. PDOs expressed that they experience stress because of additional work and they feel political interference affected their thinking and mental health that made them to perceive the job less favourable.

This finding of negatively significant relationship gets support from the findings of Bosco (2000) and Nagananda (2005).

\section{Job satisfaction and job perception}

A positive and highly significant relationship was noticed between job satisfaction of PDOs and their job perception.

Data regarding job perception and job satisfaction reveled that, majority of PDOs belonged to less favourable to favourable category of job perception and low to medium level of job satisfaction. This justifies the fact that the job satisfaction of PDOs was highly influenced by their job perception.

This finding is similar to the findings of Sontakki (1995) and Senthil et al., (1998). 
Facilities and resources at work and job perception

The Positive and highly significant relationship was exhibited between availability of facilities and resources at work and job perception of the PDOs. It means that better provision of facilities and resources in their job had positive influence on their perception.

It is because of the fact that when all the requisite facilities and resources are available in time and in required quantities, an employee feels good which results in better perception of their job. Similar results were reported by Nagananda (2005) who reported that facilities and resources had positive and significant relationship with job perception.

\section{Relationship between independent variables with job performance}

\section{Age and job performance}

A positive and highly significant relationship was observed between age and job performance of PDOs. Job performance was better with increase in the age of respondents. PDOs with middle age normally are settled in their job, developed liking for their job and they might not think of alternate opportunities at this stage. As the age of PDOs advances, their experience also increases in turn resulting in higher performance. The present findings are supported by the findings of Sundaraswamy and Perumal (1992).

\section{Education and job performance}

Education was positively and significantly related with job performance of PDOs. It implied that higher the education higher was the job performance. Higher education provides greater opportunities to acquire and retain more information by an individual in the job he is expected to perform. Such individuals will have better ability to comprehend and retrieve timely. Hence, they perform better than those with low education.

Similar results were reported by Sundaraswamy and Perumal (1992).

\section{Information seeking behaviour and job performance}

It is evident from the results (Table 2) that information-seeking behavior had non significant relationship with job performance of PDOs. PDOs were more dependent on interpersonal sources like colleagues and superiors for seeking information and few of them sought information from mass media like TV, radio, journals, newspapers, magazines etc. Further they were homogenous with respect to use of information sources for seeking job related information.

This finding is in agreement with the finding reported by Rath (1992) and Mohan (2000).

\section{Perceived work load and job performance}

Perceived workload of the respondents exhibited a non significant relationship with job performance because majority of respondents perceived their workload as heavy. More responsibilities are there on the shoulders of PDOs and multiple tasks that they have to perform. All most all the PDOs perceived their workload as heavy to medium and there was no wide variation in their perception of workload.

This finding was similar to the findings of Nagananda (2005).

\section{Job involvement and job performance}

The results indicated a positive and significant association between job involvement of PDOs and their job 
performance. A person involved in the job does the job for self-satisfaction with complete mind and soul in it. So, a feel of serious concern and deep involvement in one's job results in better performance.

The job of PDOs being a challenging one, demands full efforts in order to get acquainted with the day-to-day developments, which calls for a greater degree of involvement. It is quite natural that those who involve more in job they do perform better.
The present findings are in line with the results of Nagnur (1992) and Sunderswamy (1987).

\section{Job stress and job performance}

There was a negative and significant relationship between job stress and job performance of PDOs. This implies that the respondents who perceived higher job stress in the working area had lower level of job performance.

Table.1 Job perception and job performance of PDOs according to their education level

\begin{tabular}{|c|c|c|c|c|c|c|}
\hline Categories & \multicolumn{3}{|c|}{ Job perception } & \multicolumn{3}{c|}{ Job performance } \\
\cline { 2 - 8 } & $\begin{array}{c}\text { Bachelor } \\
\text { Degree } \\
(\mathbf{n = 9 6})\end{array}$ & $\begin{array}{c}\text { Master } \\
\text { Degre } \\
(\mathbf{n = 5 6})\end{array}$ & $\begin{array}{c}\text { Total }(\mathbf{N}= \\
\mathbf{1 5 2})\end{array}$ & $\begin{array}{c}\text { Bachelor } \\
\text { Degree } \\
(\mathbf{n = 9 6})\end{array}$ & $\begin{array}{c}\text { Master } \\
\text { Degree } \\
(\mathbf{n = 5 6})\end{array}$ & $\begin{array}{c}\text { Total (N } \\
\mathbf{1 5 2})\end{array}$ \\
\hline Low & $10(10.42 \%)$ & $9(16.07 \%)$ & $19(12.5 \%)$ & $19(19.79 \%)$ & $15(26.79 \%)$ & $34(22.37 \%)$ \\
\hline Medium & $79(82.29 \%)$ & $36(64.29 \%)$ & $115(75.65 \%)$ & $55(57.29 \%)$ & $31(55.36 \%)$ & $86(56.58 \%)$ \\
\hline High & $7(7.29 \%)$ & $11(19.64 \%)$ & $18(11.84 \%)$ & $22(22.92 \%)$ & $10(17.86 \%)$ & $32(21.05 \%)$ \\
\hline
\end{tabular}

Table.2 Correlation coefficients of independent variables with job perception and job performance of PDOs

\begin{tabular}{|c|l|c|c|}
\hline SI. & \multicolumn{1}{|c|}{ Independent variable } & \multicolumn{2}{|c|}{ Correlation coefficients (r) } \\
\cline { 3 - 4 } No & & Job Perception & Job Performance \\
\hline $\mathbf{1}$ & Age & $0.302^{* *}$ & $0.402^{* * *}$ \\
\hline $\mathbf{2}$ & Education & $-0.159^{*}$ & $0.366^{* *}$ \\
\hline $\mathbf{3}$ & Information seeking behavior & $-0.079^{\mathrm{NS}}$ & $-0.045^{\mathrm{NS}}$ \\
\hline $\mathbf{4}$ & Perceived work load & $0.273^{* *}$ & $-.0155^{\mathrm{NS}}$ \\
\hline $\mathbf{5}$ & Job satisfaction & $0.188^{*}$ & $0.313^{* * *}$ \\
\hline $\mathbf{6}$ & Job involvement & $-0.087^{\mathrm{NS}}$ & $-238^{* *}$ \\
\hline $\mathbf{7}$ & Job stress & $0.217^{* *}$ & $-0.221^{* *}$ \\
\hline $\mathbf{8}$ & Facilities and resources & $0.245^{* *}$ \\
\hline
\end{tabular}

*- Significant at 5\% level of probability

**-Significant at $1 \%$ level of probability

NS = Non- significant 
In other words, as stress increases performance decreases. Some experience stress when exposed to a particular situation like over workload, overlapping of work, time pressure and working conditions. The respondents who experience more stress in their day-to-day work may not perform better.

Similar results were reported by Sunderswamy and Perumal (1992).

\section{Job satisfaction and job performance}

A positive and highly significant relationship was observed between job satisfaction of PDOs with their job performance. When job perception and working environment are up to one's expectation then the individual derives satisfaction from his job and performs well.

\section{Facilities and resources at work and job performance}

A Positive and highly significant relationship was exhibited between availability of facilities and resources at work and job performance of the PDOs. More percentage of PDOs were in the satisfactory category of availability of facilities and resources at work. This may be because of the availability of official facilities and arrangements, office cleaning and maintenance facilities and financial resources at required time. Those PDOs performance was better who were happy with facilities and resources at work place.

Similar results were reported by Sontakki (1995) and Nagananda (2005).

\section{Factors influencing job perception and job} performance

Age, job satisfaction and facilities and resources exhibited positive and significant relationship with job perception of PDOs at
$1 \%$ level of probability. Whereas, education, job involvement showed positive and significant relationship with job perception of PDOs at 5\% level of probability.

The variables such as age, education, job satisfaction, job involvement and facilities and resources exhibited positive and significant relationship with job performance of PDOs at $1 \%$ level of probability. Whereas, job stress revealed negative significant relationship with job performance. Further, information seeking behaviour and perceived workload did not show any relationship with the job performance of PDOs.

Sixty seven per cent of the variation in job perception was explained by all independent variables put together. Job satisfaction, job stress, facilities and resources and age contributed significantly towards influencing the level of job perception of PDOs.

Fifty eight per cent of the variation in job performance was explained by all independent variables put together. Job satisfaction, facilities and resources, information seeking behaviour, age and education significantly contributed for job performance of PDOs.

\section{References}

Aimabde, R. and Manjunath, B. N., 2012, Job perception of teachers in the University of Agricultural Sciences, Bengaluru. Mysore J. Agric, Sci., 46(3): 653-654.

Ananda, K. L., Jayawardanaa, Michael O'Donnellb and Jayakodyc, J. A. S. K., 2013, Job involvement and performance among middle managers in Sri Lanka. The Int. J. Human Reso. Mngt., 24(21): 4008-4025.

Bhanu, P. and Kiran, C., 2013, Information use and information seeking behaviour of the research scholars in Punjab University, Chandigarh: A survey, Gyankosh. The J. Lib. \& Info. Mngt., 4(1): 58-59. 
Hassan, I., Tahir, M. Q. and Muhammad, A. K., 2011, The retrenchment effect on job performance with mediating effect of work life balance. African J. Business Mngt., 5(21): 8642-8648.

Kiran, T. R., 2007, Perception of organisational climate by scientists of University of Agricultural Sciences, Dharwad. M. Sc. (Agri.) Thesis, Univ. Agric. Sci., Dharwad, Karnataka (India).

Maiti, S., Jha, S. K. and Garai, S., 2011, Performance of public-privatepartnership model of veterinary services in West Bengal. Indian Res. J. Extn. $E d u$., 11(2): 1-5.

Mohan, B., 2000, A study on job performance and job satisfaction of Assistant Agricultural Officers in Northern districts of Karnataka. M. Sc. (Agri.) Thesis, Univ. Agric. Sci., Dharwad, Karnataka (India).

Nurharani, S., Nur, Z. S. and Nur, S. M. K., 2013, The impact of organizational climate on teachers' job performance. $e$ Journal Edu. Res., 2(1): 71-82.

Pounraj, A., 2013, Job performance of fisheries extension functionaries in Tamil Nadu. Madras Agric. J., 100(13): 217-223.

- Salunkhen, S. R., Pandya, R. D. and Surendra Kumar Rai, 2012 Role performance of agro-service providers and beneficiaries in Navsari district of Gujarat state. Raj. J. Extn. Edu., 20: 7-9.

Thubten, S. and Niwat, M., 2012, Performance of small holder dairy farmers' groups in the east and west central regions of Bhutan: Members' perspective. J. Agric. Extn. Rural Dev., 4(1): 23-29,

Victoria, A. O. and Benjamin, C. A., 2012, Analysis of determinants of job performance of agricultural extension worker as a leader to farmers in Nigeria. British J. Econ. Finance Mngt. Sci., 5(2): 1-21.

\section{How to cite this article:}

Bharamagoudar, M.V. and Angadi, J.G. 2019. Impact Analysis of Education Level for Job Perception and Job Performance of PDOs in Karnataka State. Int.J.Curr.Microbiol.App.Sci. 8(01): 3154-3161. doi: https://doi.org/10.20546/ijcmas.2019.801.337 